\title{
A construção da identidade militar em narrativas de pilotos da 'Esquadrilha da Fumaça': revisitando uma análise de necessidades de uso de inglês
}

\author{
La construcción de la identidad militar en narrativas de \\ pilotos 'Esquadrilha da Fumaça': revisitando un análisis de \\ las necesidades del uso del inglés
}

\begin{abstract}
The construction of military identity in the narratives of pilots from 'Esquadrilha da Fumaça': revisiting an English
\end{abstract} language needs analysis

\author{
Ana Lígia Barbosa de Carvalho e Silva ${ }^{1}$
}

\begin{abstract}
RESUMO: Este artigo tem por objetivo identificar o processo de construção discursiva identitária de um grupo de pilotos militares brasileiros pertencentes à Força Aérea Brasileira (FAB) - o Esquadrão de Demonstração Aérea (EDA) - popularmente conhecido como "Esquadrilha da Fumaça". Para tanto, realizamos um estudo qualitativo, por meio de uma revisão bibliográfica, revisitando textos nas áreas de linguística aplicada, antropologia e ciências sociais, bem como dados de uma dissertação de mestrado de cunho etnográfico (SILVA, 2016), na qual um estudo de caso explicita como o tema ora proposto tem sido abordado no Brasil. Lançamos, assim, um novo olhar para algumas narrativas dos participantes do referido estudo a respeito de suas necessidades, de modo a investigar como eles se identificam, por meio do discurso, na figura do "Fumaceiro", aquele militar que se distingue dos demais pilotos da FAB. A base teórica desta investigação apoia-se, fundamentalmente, em Castro (1990), no que se refere à constituição da identidade de militares, e Cuche (2002), quanto aos conceitos de cultura e identidade. Os resultados indicam haver uma identidade imposta ao grupo por força
\end{abstract}

\footnotetext{
${ }^{1}$ Doutoranda e mestre pelo Departamento de Linguística Aplicada do Instituto de Estudos da Linguagem (IEL) da Universidade Estadual de Campinas, Unicamp, sob orientação da Profa. Dra. Matilde V. R. Scaramucci. Especialista em Ensino de Inglês como Língua Estrangeira pela Universidade Presbiteriana Mackenzie. Membro do Grupo de Estudos em Inglês Aeronáutico (GEIA) do Instituto de Controle do Espaço Aéreo (ICEA). Contato: analigiasilva7@gmail.com Este estudo recebeu apoio financeiro da Coordenação de Aperfeiçoamento de Pessoal de Nível Superior - CAPES - Brasil. Código de financiamento 001.
} 
normativa, atribuída pela mídia e por estudiosos, que é acompanhada por uma identidade construída discursivamente pelos próprios membros do grupo.

PALAVRAS-CHAVE: Identidade. Discurso. Análise de necessidades. Inglês para pilotos.

RESUMEN: Este artículo pretende identificar el proceso de la construcción de la identidad discursiva de un grupo de pilotos militares brasileños pertenecientes a la Fuerza Aérea Brasileña (FAB), el Escuadrón de Demostración Aérea (EDA), conocido popularmente como el "Esquadrilha da Fumaça". Con este fin, realizamos un estudio cualitativo a través de una revisión de la literatura, revisitando textos en las áreas de lingüística aplicada, antropología y ciencias sociales, así como datos de una disertación de maestría de perfil etnográfico (SILVA, 2016), en el que un estudio de caso explica cómo se ha abordado el tema propuesto en Brasil. Así, echamos una nueva mirada a algunas narrativas de los participantes del referido estudio sobre sus necesidades, para investigar cómo se identifican a través del discurso, en la figura de "Fumaceiro", el militar que se distingue de los otros pilotos de la FAB. La base teórica de esta investigación se basa, fundamentalmente, en Castro (1990), con respecto a la constitución de la identidad militar, y en Cuche (2002), con respecto a los conceptos de cultura e identidad. Los resultados indican que hay una identidad impuesta al grupo por la fuerza normativa, atribuida por los medios de comunicación y académicos, que está acompañada por una identidad construida discursivamente por los miembros del grupo.

PALABRAS CLAVES: Identidad. Discurso. Análisis de necesidades. Inglés para pilotos.

ABSTRACT: This article aims to identify the discursive process of identity construction of a group of Brazilian military pilots belonging to the Brazilian Air Force (FAB) - the Air Demonstration Squadron (EDA) - popularly known as the "Esquadrilha da Fumaça". To this end, we conducted a qualitative study through a literature review, revisiting texts in the areas of applied linguistics, anthropology and social sciences, as well as we revisited data from an ethnographic master's dissertation (SILVA, 2016), in which a case study explains how the theme now proposed has been approached in Brazil. Thus, we take a new look at some narratives from the participants of the referred study about their needs, in order to investigate how they identify themselves through discourse, in the picture of the "Fumaceiro", the military officer who distinguishes himself from other FAB pilots. The theoretical basis of this research rests, fundamentally, on Castro (1990), regarding the constitution of the military identity, and Cuche (2002), regarding the concepts of culture and identity. The results indicate that there is an identity imposed on the group by normative force, attributed by the media and scholars, which is accompanied by an identity constructed discursively by the group members themselves.

KEYWORDS: Identity. Discourse. Needs analysis. English for pilots.

\section{Introdução}

A construção identitária de militares brasileiros por meio da linguagem é um tema que, apesar de instigante, parece pouco explorado em pesquisas na área de Linguística Aplicada, cuja natureza transdisciplinar permite "o diálogo de 
uma construção teórico-metodológica com outra, muitas vezes produzida em outro campo" (SIGNORINI, 2006, p. 181). Em contrapartida, em uma recente consulta a bibliotecas de diferentes faculdades da Universidade Estadual de Campinas, Unicamp, bem como ao Banco de Teses e Dissertações da Coordenação de Aperfeiçoamento de Pessoal de Nível Superior (CAPES) utilizando como descritor o termo "militares", em 200 títulos pesquisados - foi possível constatar que o assunto tem ocupado a agenda de pesquisadores de áreas afins, como a Antropologia, as Ciências Sociais e a Educação (CASTRO, 2009; LEIRNER, 2009; OLIVEIRA, 2016; SILVA, 2009; TAKAHASHI, 2009) entre outros.

Em uma obra referencial, denominada "O espírito militar: um antropólogo na caserna", Castro (1990) abriu caminho para uma série de investigações que exploram o tema, muito embora a interface entre o meio acadêmico civil e militar ainda seja bastante complexa, haja vista a dificuldade de acesso a publicações provenientes de instituições militares de ensino superior, em grandes bancos de dados ou na internet. Também Castro (1993, p. 228) ressaltou a escassez de dados disponíveis no Exército e, em especial, em outras Forças. Esse hiato pode ser explicado, ainda que minimamente, devido a possíveis resquícios de dissensões que caracterizaram o período de exceção, ocorrido no passado recente de nossa história. Como postula Soares (2016, p. 297) "[...] nos mecanismos identitários há um peso muito forte daquilo que podemos chamar [...] a sombra do passado".

Este artigo tem por objetivo identificar o processo discursivo de constituição da subjetividade e da construção da identidade de alguns pilotos militares, pertencentes ao Esquadrão de Demonstração Aérea (EDA), da Força Aérea Brasileira (FAB), popularmente conhecido como "Esquadrilha da Fumaça", por meio da análise de suas falas a respeito da necessidade de uso de inglês pelo grupo. Para tanto, em um estudo de natureza qualitativa baseado em uma revisão bibliográfica, apresento recortes de uma dissertação de mestrado (SILVA, 2016), desenvolvida no Instituto de Estudos da Linguagem (IEL) da Unicamp, por meio da qual foram ouvidos tanto pilotos em atividade como veteranos, 
cobrindo mais de 30 anos de existência do grupo. Tal pesquisa anterior surgiu a partir de observações de sua autora, quando trabalhava como professora de inglês para membros da equipe, em aulas particulares, na sede da instituição. Foi, então, possível adentrar o grupo e conhecer, por meio de uma análise de necessidades, o ensino e a avaliação de proficiência em inglês no âmbito do Comando da Aeronáutica, COMAER, bem como identificar as principais situações de uso dessa língua pelos pilotos da Esquadrilha da Fumaça.

O estudo de caso foi o percurso metodológico escolhido na dissertação mencionada. Foram utilizados, além de consulta a documentos no acervo histórico e fotográfico do grupo, outros procedimentos, como a observação participante, notas de campo, entrevistas e grupos focais, o que possibilitou a triangulação de dados para análise. À época, o desenho metodológico da dissertação não foi considerado, de fato, uma etnografia. Hoje, revendo aquela pesquisa sob a perspectiva de Khan (2017), é possível argumentar que etnografias e estudos de caso sejam desenhos metodológicos complementares, pois se, por um lado, a etnografia possibilita ao pesquisador a entrada no mundo do participante, viabilizando a percepção de como ele constrói sentido em seu entorno, por outro, o estudo de caso, conforme Gil (2009), oferece uma rica oportunidade de se desenvolver um estudo em profundidade da unidade de análise escolhida.

É possível, agora, revisitarmos os dados daquela investigação a partir de um novo olhar, na esteira do que afirma, sobre a própria pesquisa, Cavalcanti (2006, p. 236): "Se assim como no pós-modernismo, dentro de uma perspectiva pós-colonial, tudo está em fluxo, também meu olhar sobre a pesquisa está em movimento, é temporário, sofre alterações à medida que releio o que escrevo."

Em meio às falas dos participantes na análise de necessidades, anteriormente realizada, busco conhecer, neste texto, sob a ótica de Cuche (2002), não apenas o que dizem sobre o inglês que precisam, mas aquilo que os leva a dizer o que dizem. Muito distante de tentar entender cultura militar de forma essencializada e homogeneizante, junto-me a Maher (2007), que, citando Brian Street, assevera que "o grande desafio não é descrever as crenças e os 
comportamentos de um dado grupo cultural: é entender a lógica por detrás dessas crenças e comportamentos" (MAHER, 2007, p. 262). Vale lembrar que não há uma padronização sobre o que seja cultura. Neste texto, alinho-me a Maher (2007, p. 261), para quem a cultura é "um sistema compartilhado de valores, de representação e de ação: é a cultura que orienta a forma como vemos e damos inteligibilidade às coisas que nos cercam; é ela que orienta a forma como agimos diante do mundo e dos acontecimentos"; é uma "construção discursiva", uma "produção histórica", "um processo ativo na construção de significados", e não uma vinculação biológica, ou uma herança.

Este artigo está organizado do seguinte modo: após esta introdução, apresento o referencial teórico que norteou as reflexões propostas, a partir de uma revisão bibliográfica sobre conceitos como "representação" e "identidade" no âmbito militar. Em seguida, enumero as principais características do EDA e retomo alguns dados da dissertação de Silva (2016) que elucidam os conceitos abordados. Por fim, apresento narrativas que possibilitam a percepção mais clara da constituição identitária de membros do grupo e traço algumas considerações finais.

\section{Representação e identidade no âmbito militar}

Os militares são categorizados, em geral, como "um grupo fechado, tradicional e altamente hierárquico, no qual se configura a preeminência da coletividade sobre os indivíduos [...]" (SILVA, 2009, p. 108). Todavia, algo que merece ser observado, desde o início de nossas reflexões, é a possibilidade de haver certos traços característicos que distinguem cada uma das Forças militares brasileiras.

Tal fenômeno é denominado por Castro (1990) "espíritos das Forças". Em seu estudo, o autor relata, por exemplo, que cadetes do Exército tinham representações diferentes quanto ao "espírito" da Marinha, do Exército e da Aeronáutica. Sob a perspectiva desses militares, o espírito do Exército era considerado mais "militar" e mais "comprometido com aos problemas nacionais"; 
já o espírito da Marinha era visto como "mais elitista, aristocrático" (CASTRO, 1990, p. 98), enquanto o espírito da Aeronáutica era tido como "'’mais tranquilo', 'mais paisano', de menor atenção à hierarquia e à disciplina que nas outras Forças, e também de menor enquadramento" (CASTRO, 1990, p. 99). Em oposição ao Exército, os militares da Aeronáutica eram, então, considerados "um pessoal mais malandro, meio playboy e tal", ou ainda "mais mente aberta, mais avançados", representantes de um "militarismo diferente", mais "voltado para os estudos" e para o "lado técnico" de suas atividades (CASTRO, 1990, p. 99). Tais afirmações colocam-nos diante de uma primeira, e intricada, perspectiva sobre a identidade militar, especificamente de membros da Aeronáutica, que se perfaz por meio do discurso e da oposição às outras Armas, pela visão singular de um grupo de cadetes do Exército, conforme Castro (1990).

O conceito de "espírito", portanto, é aqui tomado como parte de um sistema de representação, ou seja, como "um processo discursivo, um processo de significação sempre culturalmente determinado e sócio-historicamente construído" (MAHER, 2010, p. 37). Similarmente, a identidade está sempre "em processo", "sendo formada" (HALL, 2006, p. 38), marcada pela diferença, pela dialética da alteridade, pela existência do outro (CUCHE, 2002; SILVA, 2000; WOODWARD, 2000). Assim, o "militar da aeronáutica" não pode ser compreendido fora de seu contexto já que, como ensina Hall (1997, p. 61), as pessoas, os eventos do mundo "[...] não têm em si qualquer significado estabelecido, final ou verdadeiro. Somos nós - na sociedade, nas culturas humanas - que fazemos as coisas significarem, que significamos".

Esse é, basicamente, o argumento de Cuche (2002), que discorre, de forma ampla e aprofundada, sobre as relações entre os conceitos de cultura e identidade. Seus ensinamentos iluminam nossas reflexões por meio de uma concepção relacional e situacional de identidade cultural. Segundo esse autor, é na relação social, de forma contextualizada e situada no tempo e no espaço, que o indivíduo afirma ou nega sua identidade, pois a identidade "é uma construção que se elabora em uma relação que opõe um grupo aos outros com os quais está em contato" (CUCHE, 2002, p. 182). 
Outros conceitos trazidos por Cuche (2002), que são balizadores destas reflexões, referem-se às noções de "autoidentidade", entendida como uma representação discursiva definida por si mesmo, e "heteroidentidade", demarcada pelos outros. Para esse autor, a autoidentidade poderá gozar de maior ou menor legitimidade a depender da relação de forças entre os grupos em contato, porém a heteroidentidade poderá provocar uma "identidade negativa", podendo chegar à situação extremada de levar as pessoas ao desprezo por si mesmas.

Vale destacar, ainda, a noção de "estratégias de identidade", proposta por Cuche (2002). Partindo do pressuposto de que as identidades não são fixas, absolutas, mas relativas, dinâmicas e multidimensionais, o autor sugere que elas podem servir como instrumento de manobra. Dessa forma, o indivíduo, enquanto ator social, apropria-se de seus recursos de identidade de modo estratégico, ora enaltecendo, ora ocultando atributos que deseja expor ou apagar, conforme a situação, posicionando-se segundo interesses diversos a fim de atingir determinado objetivo.

Nesse sentido, Brown e Levinson (1987) argumentam que as pessoas se auxiliam mutuamente na tentativa de manter ou, ao menos, tentar minimizar uma ameaça à própria "fachada", definida por Goffman (2011, p. 13) como "o valor positivo que uma pessoa efetivamente reivindica para si mesma através da linha que os outros pressupõem que ela assume durante um contato particular".

\section{Dados da análise de necessidades: um novo olhar}

\section{O Esquadrão de Demonstração Aérea (EDA) - "Esquadrilha da Fumaça"}

O EDA foi criado em 1952, com a missão oficial de realizar demonstrações aéreas a fim de difundir, em âmbito nacional e internacional, a imagem institucional da FAB. Dentre suas atribuições estão o compromisso de representar a $F A B$, no exterior, como instrumento diplomático e difundir a Política de 
Comunicação Social do Comando da Aeronáutica (COMAER), atuando como "[...] verdadeiros 'embaixadores' do Brasil no exterior (SILVA, 2007, p. 70)".

Os pilotos da Esquadrilha da Fumaça são oficiais militares, pertencentes ao quadro de Aviadores da FAB. Permanecem no EDA por apenas alguns anos de suas carreiras, no máximo cinco, exceto o comandante, que ocupa o cargo por dois anos, em média. São todos do sexo masculino, embora haja no grupo integrantes mulheres, pertencentes a outros quadros e patentes militares.

Tais pilotos exercem, antes e depois de suas demonstrações aéreas, não apenas funções técnicas ligadas à atividade aérea, mas também funções administrativas e de comunicação social (BRASIL, 2014a, 2014b), tais como o contato com membros de grupos similares, o público, a imprensa falada e escrita. Participam também de eventos aeronáuticos, como feiras, shows aéreos, exposições e intercâmbios internacionais (SILVA, 2016).

O grupo foi identificado por Silva $(2007$, p. 7) como uma "equipe de alta performance", que tem como característica compartilhar objetivos e sentimentos comuns, a fim de potencializar a capacidade técnica de cada membro. Tal sentimento compartilhado de coesão e homogeneidade interna é denominado no âmbito militar "espírito de corpo" (CASTRO, 1990) e constitui um dos valores perseguidos pela equipe. É o que se pode observar na foto, extraída da dissertação de Silva (2016), e nos dizeres que a acompanham (Figura 1): "A Esquadrilha sendo a Esquadrilha: espírito de corpo e trabalho em equipe".

Figura 1 - Espírito de corpo e trabalho em equipe

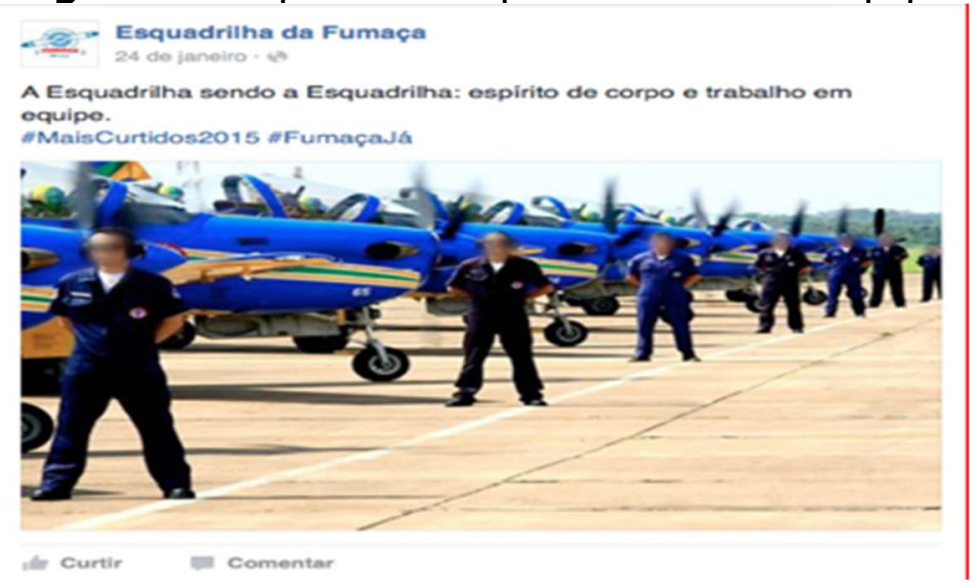


Fonte: Silva (2016)

Percebe-se, aí, a manifestação da representação discursiva por meio da autoidentidade, conforme Cuche (2002), em que o próprio grupo se define como coeso e sinérgico. Como explica Woodward (2000, p. 15, grifo do original), as pessoas - e aqui entendemos que também os grupos - "assumem suas posições de identidade e se identificam com elas". Há que se observar que, até o dia 26 de maio de 2016, essa publicação havia sido recebida como muito positiva pelos usuários do Facebook, por meio de mais de 7.300 "curtidas" e 616 compartilhamentos.

\section{O sentimento de pertencimento ao grupo}

Dando sequência às nossas análises, retomamos o trecho em que Silva (2016) relata como o sentimento de "pertencimento ao grupo", sugerido por Silva (2007), foi observado durante uma conversa informal com um dos pilotos do EDA. Na ocasião, este a repreendeu por ter utilizado o termo "ex-Fumaceiro" para referir-se a um Oficial Aviador veterano, ex-integrante do grupo. O piloto contou várias estórias e advertiu a pesquisadora: "Não existe, entre nós, exFumaceiro. Uma vez Fumaceiro, para sempre Fumaceiro!". Como ensina Bizon (2013, p. 103), citando Wortham (2001), por meio de narrativas, é comum que o indivíduo reforce e algumas vezes recrie o tipo de pessoa que ele é. No caso, um membro do grupo.

Para Brubaker (2002), "grupo" é um conceito-chave para diversas áreas, como a sociologia e a ciência política, entre outras, e, aqui acrescentamos, também para a Linguística Aplicada. No entanto, para escapar de uma representação que nos remeta a uma entidade estática, ou a um organismo fixo, concreto, tangível, o autor sugere existir um "espírito de grupo"2, entendido como "um evento"3 (BRUBAKER, 2002, p. 168, tradução nossa), algo construído, contingente, variável e flutuante. Tal "espírito de grupo" caracteriza-se por

\footnotetext{
2 No original: "groupness".

3 No original: "an event".
} 
momentos de coesão e solidariedade, gerados por propósitos ou sentimentos comuns, o que não ocorre, por exemplo, em um mero ajuntamento de indivíduos que compartilham o espaço de um grande local de compras.

Tais considerações teóricas nos ajudam a compreender como o EDA é, de fato, "construído e flutuante", pois renova-se com a substituição aproximada de $25 \%$ de seus pilotos a cada ano. A permanência dos integrantes no "Esquadrão", ou "grupo" no meio militar, é efêmera, temporal. Assim, embora se intitulem "Para sempre Fumaceiros", os pilotos do EDA possuem certa identidade enquanto em atividade na equipe, porém, passados 3 ou 4 anos, voltam a desempenhar papéis comuns aos demais pilotos da $F A B$, e têm sua identidade novamente negociada e demarcada.

Posicionamentos sobre a língua inglesa necessária ao EDA e implicações identitárias

Silva (2018, p. 127) sustenta que a proficiência em inglês necessária aos pilotos do EDA pressupõe uma visão contemporânea de língua e linguagem, que abarca tanto o chamado Inglês Geral, como o Inglês Específico para Aviação, afastando-se da concepção idealizada e absoluta de um suposto falante "nativo", que diante da especificidade das comunicações aeronáuticas, também deveria ter sua proficiência questionada. Todavia, ao serem indagados sobre que tipo de inglês julgavam ser necessário à equipe para o desempenho de suas atividades funcionais, as opiniões dos "Pilotos Veteranos" e dos "Pilotos em Atividade" apresentaram posicionamentos divergentes (SILVA, 2016). Todos os integrantes do primeiro grupo, que tinham mais experiências em viagens internacionais com o EDA, afirmaram que tanto o Inglês Geral, ou English for General Purposes (EGP), como o Inglês para Fins Específicos, English for Specific Purposes (ESP), em contexto de aviação, ou Aviation English (AE), eram necessários. Assim manifestou-se o participante FBL: 
79. $\mathrm{FBL}^{4}$ : eu acho assim (+) o piloto tá pronto, né [...] ele tem que estar operacionalmente pronto né" $(+)$ um piloto seguro e capaz $(+)$ com qualidade $(+)$ e tem que saber falar inglês $(+)$ pra representar a Força Aérea e o Brasil (+) porque não é só a Força Aérea (+) é o Brasil (SILVA, 2016, p. 193-194) $)^{5}$.

Entretanto, os integrantes do segundo grupo, Pilotos em Atividade, disseram, em sua maioria, que apenas o chamado "Inglês Instrumental", ou "Técnico", voltado para o voo, era necessário a todos os membros do grupo, limitando o uso de EGP apenas como desejável para alguns poucos membros. É o que se pode depreender do relato que se segue:

40. FMR: olha (+) eu acho o seguinte $(+)$ falando de Esquadrão $(+) 0$ Esquadrão (EDA) tem que ter algumas peças chaves pra esse / $(+)$ o DESEJÁVEL $(+)$ o IDEAL $(+)$ o NIRVANA $(+)$ é que todo mundo seja fluente, $(+)$ more nos Estados Unidos 2 anos e a FAB custeie tudo isso (em tom irônico) $(+)$ mas a gente sabe que isso nunca vai acontecer, $(+)$ mas eu acho que o esquadrão / existe um IDEAL e existe um MÍNIMO, (+) o mínimo é que você tenha uma peça chave lá (+) uma peça chave aqui $(+)$ que consiga fazer isso (comunicar-se em inglês) $(+)$ já que as entrevistas elas podem ser agendadas $(+)$ o intercâmbio $(+)$ o cara tem condições de se preparar $(+)$ então eu acho que tem $o$ IDEAL' e tem o MÍNIMO, (+) no mínimo você tem que ter ali uns 4 caras que consigam aí(+) ser fluentes, (+) ou dar uma entrevista, $(+)$ porque não adianta, $(+)$ seria uma UTOPIA também chegar e falar assim (+) não, (+) qualquer piloto do EDA pode dar uma entrevista em inglês' ${ }^{\prime}+$ ) qualquer hora (+) andando na rua, (SILVA, 2016, p. 172).

Embora os Pilotos em Atividade afirmem não ter dificuldades no uso de inglês para aviação, durante voos internacionais, admitem, em alguns relatos, enfrentamentos em relação à produção oral em EGP. Chegam a se comparar com pilotos de outros países, em um típico exemplo de "identidade negativa" (CUCHE, 2002, p. 184), porém não exógena ao grupo, como explicitado pelo autor, mas ao contrário, autoimposta. É o que vemos por meio da reprodução do seguinte trecho:

\footnotetext{
${ }^{4}$ Nos trechos de relatos transcritos neste estudo, foram mantidos os pseudônimos utilizados, por questões éticas, na pesquisa original, conforme se segue: $\mathrm{P}=$ Pesquisadora; $\mathrm{FBL}=$ Fumaça Blue; Fumaça Orange; FMR: Fumaça Marrom; FRX: Fumaça Roxa. As cores diferentes, em inglês e português, distinguem duas categorias de participantes: os primeiros eram Pilotos Veteranos; os segundos Pilotos em Atividade.

${ }^{5}$ Os grifos, nos relatos transcritos, foram mantidos como no original.
} 
41. FRX: só um detalhe, $(+)$ (todos ficam em silêncio) a gente foi lá na "Patruille de France" (grupo de demonstração aérea da França) e TODOS falavam inglês, $(+)$ inclusive os graduados (mecânicos) (+) TODOS falavam,

A esse comentário, outro participante, FMR, imediatamente reagiu:

42. FMR: é, (+) é outro país, né" is:

Na sequência, FPA juntou-se à discussão e acrescentou:

43. FPA: tem a ver com a Educação, né' (+) não é aqui (no EDA) que se resolve, $(+)$ isso tem que ser focado anteriormente

Outro participante, FPR, em seguida, disparou:

44. FPR: independente se o cara foi para a "Patruille de France" (+) ou não (+) lá (na França) TODA A FORÇA AÉREA FRANCESA FALA INGLÊS (SILVA, 2016, p. 172).

Observa-se, assim, o movimento discursivo pelo qual os Pilotos em Atividade utilizam certa "estratégia de identidade" (CUCHE, 2002), ao afirmarem que apenas o inglês técnico Ihes seria necessário. Assim, minimizam a relevância da necessidade de uso do EGP por cada membro do grupo, individualmente, compartilhando tal responsabilidade entre todos os seus integrantes, o que caracteriza o sentimento de "espírito de corpo" (CASTRO, 1990) necessário para dar conta da missão que lhes é conferida. É o que se pode inferir a partir do relato que se segue:

50. P: e a questão da parte social $(+)$ coquetéis $(+)$ festas $(+)$ recepções $(+)$ vocês têm que ir" iṣ̌p:

FVH: [...] vai naquilo, né' $(+)$ você conversa de acordo com o / (+) naturalmente $(+)$ se você não manja muito' $(+)$ né(+) você vai puxar alguém, $(+)$ vai com alguém, né" $(+)$ e acaba ficando lá, (+) fica mais quieto, tal (+) nesse estilo assim, né (SILVA, 2016, p. 175).

Ao interpretar tais relatos, Silva (2016, p. 175-176) assim argumenta:

[...] os dados nos levam a crer que o "agir em grupo" sugerido nos relatos não implicaria necessariamente uma forma de ajuda mútua, para que, somando forças, ninguém se sobrecarregasse, e, de modo sinérgico, o grupo se fortalecesse. Ao contrário, parece assumir a conotação de substituição de papéis. Uns chamariam para si mais tarefas para, em nome do grupo e do sucesso da missão, compensar eventuais deficiências pontuais de proficiência na língua inglesa de outros. Por esse enfoque, há que se discernir o quanto o eu coletivo, sob a forma do agir em grupo e do espírito de corpo, pode estar se transformando em um arriscado esconderijo para as possíveis limitações individuais de alguns. 
De fato, os Pilotos em Atividade parecem realizar manobras identitárias estratégicas de posicionamento, com o fito, nem sempre explícito, de preservar a autoimagem positiva do grupo. Por vezes, negociam a própria identidade (CUCHE, 2002) distinguindo-se dos demais pilotos militares da FAB por desempenharem também funções, em solo, de representação diplomática. Por outras, se autodefinem tão somente como pilotos, assemelhando-se aos demais companheiros de farda. Já, os Pilotos Veteranos, mais experientes e maduros, afirmaram unanimemente que tanto EGP como ESP são necessários ao grupo, e não apenas desejáveis.

Assim, Silva (2016, p. 173-174) sustenta que:

\begin{abstract}
O grupo formado pelos Pilotos em Atividade dá mostras de que constrói, repensa e questiona sua própria identidade a partir da imagem que traz consigo de outros grupos semelhantes. Em seus relatos, alguns deixam transparecer o quanto se percebem como membros de uma Força Aérea - e de um país - que apresenta certas deficiências em seu sistema educacional, em particular no tocante ao processo de ensino/aprendizagem de inglês, o que os difere de seus companheiros estrangeiros. Os dados mostram que os participantes veem nessa deficiência social sutilmente apercebida, e também na diferença em relação a seus companheiros estrangeiros, a justificativa para se eximirem da obrigatoriedade - ou da necessidade - de "todos estarem preparados" para agir por meio do idioma, tanto em situação de voo como em solo. Por conseguinte, admitir que o inglês é necessário a todos os pilotos do grupo, e num contraponto, assumir, ainda que veladamente, que nem todos estão capacitados para agir em qualquer circunstância - como os franceses, ou os chilenos parecem estar - seria para os Pilotos em Atividade o mesmo que assumir suas próprias deficiências e limitações.
\end{abstract}

Por meio de um posicionamento que, a nosso ver, parece não intencional, os Pilotos em Atividade, buscam relativizar, em suas falas, a necessidade individual de produção oral em inglês EGP, que prefeririam não existir. É preciso ressaltar, todavia, que não foram encontrados relatos contendo sentimentos negativos quanto ao uso da língua inglesa em voo, por esses mesmos pilotos. 


\section{Narrativas}

"É latino!"

Em um relato sobre uma viagem ao exterior, um Piloto Veterano demonstrou receio de perder credibilidade diante de seu interlocutor, diante de uma situação de uso de EGP, julgando poder ser passível de algum tipo de preconceito por, supostamente, pertencer a um grupo "menos favorecido", pelo simples fato de não dominar a língua hegemônica, o inglês.

56. FBL: então (+) eu estava na França $(+)$ fui fazer um intercâmbio na Academia (militar) $(+)$ aí eu cheguei na Academia era tipo duas da manhã, $(+)$ o voo atrasou $(+)$ pegamos lá um trem $(+)$ e quem me atendeu foi o soldadinho da guarda (+) dezoito anos $(+)$ e falando um inglês como se fosse uma língua nativa $(+)$ então assim $(+)$ um francês $(+)$ de dezoito anos $(+)$ falando inglês fluentemente $(+)$ eeh'sem erros' e nós conversando ali'(+) e eu com um nível de inglês abaixo do dele, $n e^{\prime}(+)$ assim (+) (gesticula e leva a mão à boca)

$P$ : você se sentiu mal"

FBL: me senti envergonhado, $(+)$ porque fica um país $(+)$ imagina $(+)$ um soldado DE DEZO::ITO ANOS, $(+)$ falando na época com um [...] da Força Aérea Brasileira (por questões éticas, omitimos aqui a patente do oficial) (+) e já tem aquela impressão, né (+) (em tom de descrédito) caramba (+) é latino, (SILVA, 2016, p. 179).

É possível notar, nesse trecho, uma identidade negativa que é autoimposta pelo próprio piloto, pelo fato de não falar bem inglês geral. Não é, portanto, definida por outras pessoas, como Cuche (2002) afirma ser comum ocorrer. Julga que o soldado iria rotulá-lo como "latino", uma representação que, por sua fala, apresenta-se como negativa. A leitura que o piloto faz de si próprio parece ser de inferioridade em relação ao soldado francês, mais jovem, igualmente "estrangeiro" quanto ao uso de inglês, e em posição militar hierárquica subalterna. O piloto demonstra, no trecho citado, certo grau de constrangimento, que pode ser observado nas interações face a face, conforme preconizado por Goffman (2011), confirmando ser mesmo na relação com o outro que a identidade se constrói, pois como explica Woodward (2000, p. 18), "É por meio 
dos significados produzidos pelas representações que damos sentido à nossa experiência e àquilo que somos".

"O churrasco"

$\mathrm{Na}$ narrativa anterior, percebemos a presença do sentimento negativo autoimposto de constrangimento (GOFFMAN, 2011), por parte de um piloto veterano do EDA, por não falar inglês geral como achava que deveria. $\mathrm{Na}$ narrativa 2, que se segue, o sentimento gerado, por igual motivo, caracteriza-se como frustração.

57. FOG: uma das minhas frustrações foi não ter recebido os americanos e canadenses ( + ) (aqui ele se refere a uma visita oficial ao EDA, realizada por pilotos daqueles países) [...] eu gostaria de ter recebido eles (sic) NA MINHA CASA, (+) fazer um churra: :sco pra eles, $(+)$ eu cheguei a pensar nisso, $(+)$ mas eu falei, $(+)$ mas eu vou estar lá como anfitrião e me escorando nos outros pra tentar falar'e às vezes não entender' ${ }^{(+)}$aí eu achei por bem não fazer, entendeu' ${ }^{(+)}$por esse lado eu senti que eu NÃO completei a minha missão naquele ato específico, né'(SILVA, 2016, p. 180).

A situação em que os fatos ocorrem, um churrasco, pode aparentar ser bastante informal e despretensiosa. Todavia, o evento relatado revestia-se de especial importância porque seria o momento em que o piloto, líder da equipe, iria exercer a atribuição que chamou para si de receber, em sua própria casa, os colegas estrangeiros de outros grupos similares. Por esse entendimento, 0 churrasco seria parte de sua função como comandante, e por isso caberia a ele agir, em nome do grupo, como anfitrião, por meio do inglês geral. A fim de melhor compreendermos essa narrativa é preciso uma breve reflexão sobre 0 conceito de subjetividade.

\footnotetext{
"Subjetividade" sugere a compreensão que temos sobre o nosso eu. 0 termo envolve os pensamentos e as emoções conscientes e inconscientes que constituem nossas concepções sobre "quem nós somos". A subjetividade envolve nossos sentimentos e pensamentos mais pessoais. (WOODWARD, 2000, p. 55).
} 
Ao assumir a responsabilidade de falar, em inglês, em nome do grupo, o piloto em questão assumia posições e com elas se identificava, dando voz a seus sentimentos mais íntimos na construção de sua identidade como líder do grupo. É nesse sentido que, segundo Woodward (2000), a subjetividade e a identidade são conceitos que se entrelaçam, pois é no contexto social que a linguagem e a cultura dão significado à experiência que temos de nós mesmos.

"A coletividade"

Em um último relato, o mesmo participante da narrativa anterior fala sobre o modo como evitava expor-se, em situações sociais de uso de EGP, em eventos com o grupo. O sentimento manifesto, por não dominar a língua inglesa nessas situações, parece-nos mais forte que nas narrativas anteriores, assemelhando-se à sensação de angústia.

57. FOG: e eu posso te garantir que muitos dos pilotos com quem eu convivi'(+) também sofriam do mesmo mal que o meu (risos), (+) é:: $(+)$ de' muitas das vezes SE ESCONDER na coletividade' com medo de receber ali'vamos chamar assim, um público cujo idioma seja o inglês, P: aham

[...] FOG: pra você ter uma ideia $(+)$ na minha primeira passagem (pelo EDA) a insegurança' (+) ela 'ela estava visível' mas eu conseguia' $(+)$ entre aspas'(+) ME ESCONDER'POR TRÁS DO GRUPO, (+) mas a partir do momento que você está como Comandante' você está à frente do grupo' e aí você não tem como se esconder' (risos) então na verdade eu TENTAVA' $(+)$ a todo custo' me preparar' nem que fosse DECORANDO algumas palavras' ou textos ou situações' $(+)$ pra que eu pudesse' não' (+) é:: não digo BEM representar' (+) mas NÃO representar TÃ ::O MAL assim a Esquadrilha' a Força' (+) o país' né" [...] (+) EU CONSEGUIA ME ESCONDER NA MINHA COLETIVIDADE, $(+)$ nós tínhamos pessoas no grupo que falavam muito bem $[\ldots](+)$ e toda vez que eu me vi numa situação COMPLICADA' (+) eu ficava debaixo da asa desses amigos, entendeu" (SILVA, 2016, p. 184 -185).

No trecho citado acima, o piloto lançava mão de recursos diversos como memorização de frases prontas, utilização de frases curtas, além da ajuda de amigos, a fim de diluir-se no anonimato que o grupo Ihe propiciava. Essa ação coordenada e conjunta alinha-se, sobremaneira, ao conceito de "espírito de grupo", conforme Brubaker (2002), que pressupõe um senso de solidariedade e 
identidade corporativa, que, segundo o relato, tem funcionado muito bem entre esses pilotos. Porém, é preciso ter em mente que tais atitudes, caracterizadas no meio militar como "espírito de corpo" (CASTRO, 1990), podem vir a se confundir, na prática, com uma força atenuante de ameaça à fachada de membros do grupo, na tentativa de se apagar algumas de suas possíveis limitações.

\section{Considerações Finais}

A Esquadrilha da Fumaça, criada com a finalidade precípua de "representar o Brasil e a FAB", possui uma heteroidentidade que lhe é imposta, a priori, não só pelos documentos normativos que a constitui (BRASIL 2014a; 2014b) como também lhe é atribuída pela mídia, e até mesmo por estudiosos, que a classificam como um grupo de alta performance (SILVA, 2007), dotado de "espírito de corpo" (CASTRO, 1990; SILVA, 2016). Paralelamente a isso, a identidade da equipe é também autoimposta, por exemplo, quando o grupo chama para si certas qualidades, como a coesão e a sinergia, fruto do trabalho em equipe. Em relatos isolados, Pilotos em Atividade e Pilotos Veteranos demonstraram, similarmente, traços de constituição de identidade autoimposta negativa, porém somente em relação ao uso de EGP. Não há relatos semelhantes quanto ao uso de inglês específico para aviação, utilizado em voos internacionais.

Em meio a esses movimentos discursivos, constitutivos da identidade do grupo, surge a figura do "Fumaceiro", que se perpetua como membro do grupo.

É justamente por meio da interlocução com a pesquisadora, e com os demais membros da equipe, durante a pesquisa aqui referenciada, que os pilotos do EDA dão vozes a suas opiniões, pensamentos, e, por que não, também a sentimentos negativos, frente aos enfrentamentos no uso da língua inglesa no âmbito profissional.

Assim como Cuche (2002, p. 183-184), entendemos que "a identidade é sempre uma concessão, uma negociação", entre a heteroidentidade, que para o EDA é determinada por força normativa, e a autoidentidade, que se perfaz por meio da fala de seus pilotos. Em suma, para além de uma identidade exógena, 
refletida na imagem totalizante de perfeição que se possa ter dessa equipe de pilotos, por vezes refletida no senso comum, é bom lembrar a humanidade de cada um deles, manifesta em suas próprias palavras, ao finalizar suas demonstrações aéreas junto ao público, quando o locutor reafirma: "dentro de cada aeronave, há um coração".

\section{Referências}

BIZON, Ana Cecília Cossi. Narrando o exame Celpe-Bras e o convênio Pec-G: a construção de territorialidades em tempos de internacionalização. 2013. $445 \mathrm{f}$. Tese (Doutorado em Linguística Aplicada) - Instituto de Filosofia e Ciências Humanas, Universidade Estadual de Campinas, SP, 2013. Disponível em: http://www.ufrgs.br/acervocelpebras/arquivos/textos-publicados/tese-anacecilia-bizon. Acesso em: 6 fev. 2018.

BRASIL. Ministério da Defesa. Comando da Aeronáutica. RICA 21-110: Regimento Interno do Esquadrão de Demonstração Aérea da Força Aérea Brasileira. 2014a.

BRASIL. Ministério da Defesa. Comando da Aeronáutica. RICA 21-44: Regulamento Interno do Esquadrão de Demonstração Aérea da Força Aérea Brasileira. 2014b.

BROWN, Penelope; LEVINSON, Stephen C. Politeness. some universals in language usage. Cambridge: Cambridge University Press, 1987. (Studies in Interactinal Socilinguistics, 4).

BRUBAKER, Rogers. Ethnicity without groups. Archives Européennes de Sociologie, Cambridge, GB. v. 43, n. 2, p. 163-189, 2002. Disponível em: https://www.cambridge.org/core/services/aop-cambridgecore/content/view/ODCD6F79DE1F989E4C2AA6E201F6FEEF/S00039756020010 66a.pdf/ethnicity_without_groups.pdf. Acesso em: 6 fev. 2018.

CASTRO, Celso. A origem social dos militares. novos dados para uma antiga discussão. Novos Estudos, São Paulo, SP, n. 37, p. 225-231, nov. 1993.

CASTRO, Celso. Em campo com os militares. In: CASTRO, Celso; LEIRNER, Piero (org.). Antropologia dos militares: reflexões sobre pesquisas de campo. Rio de Janeiro, RJ: FGV, 2009. p. 13-30.

CASTRO, Celso. O espírito militar. um antropólogo na caserna. Rio de Janeiro, RJ: Jorge Zahar, 1990. 
CAVALCANTI, Marilda do Couto. Um olhar metateórico e metametodológico em pesquisa em linguística aplicada: implicações éticas e políticas. In: LOPES, Luiz Paulo Moita (org.). Por uma linguística aplicada indisciplinar. São Paulo, SP: Parábola, 2006. Cap. 10, p. 233-252.

CUCHE, Denys. A noção de cultura nas ciências sociais. Tradução de Viviane Ribeiro. 2. ed. Bauru, SP: EDUSC, 2002.

GIL, Antônio Carlos. Estudo de caso. São Paulo: Atlas, 2009.

GOFFMAN, Erving. Ritual de interação: ensaios sobre o comportamento face a face. Tradução de Fábio Rodrigues da Silva. Petrópolis: Vozes, 2011.

HALL, Stuart. A identidade cultural na pós-modernidade. Tradução de Tomaz Tadeu da Silva e Guacira Lopes Louro. 11. ed. Rio de Janeiro, RJ: DP \& A, 2006.

HALL, Stuart. The work of representation. In: HALL, Stuart (org.).

Representation: cultural representations and signifying practices. Londres: Thousand Oaks; New Deli: Sage: Open University, 1997. p. 2-73.

KHAN, Kamran. (ed.). The risks and gains of a single case study. In: MARTINJONES, Marilyn; MARTIN, Deirdre (ed.). Researching multilingualism: critical and ethnographic perspectives. New York: Routledge, 2017. p. 60-72.

LEIRNER, Piero. Etnografia com militares: fórmula, dosagem e posologia. In: CASTRO, Celso; LEIRNER, Piero (org.). Antropologia dos militares. reflexões sobre pesquisas de campo. Rio de Janeiro, RJ: FGV, 2009. p. 31-52.

MAHER, Terezinha de Jesus Machado. A educação do entorno para a interculturalidade e o plurilinguismo. In: KLEIMAN, Ângela Bustos Romero de; CAVALCANTI, Marilda do Couto (org.). Linguística Aplicada: faces e interfaces. Campinas, SP: Mercado de Letras, 2007. p. 255-270.

MAHER, Terezinha de Jesus Machado. Políticas linguísticas e políticas de identidade: currículo e representações de professores indígenas na Amazônia ocidental brasileira. Currículo sem Fronteiras, Pelotas, RS, v. 10, n. 1, p. 33-48, jan./jun. 2010. Disponível em:

http://www.curriculosemfronteiras.org/vol10iss1articles/maher.pdf. Acesso em: 5 fev. 2018.

OLIVEIRA, Eliézer Rizzo de. In: CASTRO, Celso; MARQUES, Adriana (org.). Pesquisando os militares brasileiros. experiências de cientistas sociais. Curitiba, PR: Prismas, 2016. p. 103-148.

SIGNORINI, Inês. A questão da língua legítima na sociedade democrática: um desafio para a linguística aplicada contemporânea. In: LOPES, Luiz Paulo da 
Moita (org.). Por uma linguística aplicada indisciplinar. São Paulo, SP: Parábola, 2006. p. $169-190$.

SILVA, Ana Lígia Barbosa de Carvalho e. Análise de necessidades para a definição da proficiência em inglês dos pilotos da Esquadrilha da Fumaça. In: SCARAMUCCI, Matilde V. R.; TOSQUI-LUCKS, Patrícia; DAMIÃO, Silvia Matravolgyi (org.). Pesquisas sobre inglês aeronáutico no Brasil. Campinas: Pontes, 2018. p. 115-132.

SILVA, Ana Lígia Barbosa de Carvalho e. Uma análise de necessidades de uso da língua inglesa por oficiais aviadores do esquadrão de demonstração aérea da Força Aérea Brasileira. 2016. 278 f. Dissertação (Mestrado em Linguística Aplicada) - Universidade Estadual de Campinas, Campinas, SP, 2016. Disponível em:

http://www.bibliotecadigital.unicamp.br/document/?code=000973844\&opt=1. Acesso em: 22 jul. 2019.

SILVA, Cristina Rodrigues da. Explorando o "mundo do quartel". In: CASTRO, Celso; LEIRNER, Piero (org.). Antropologia dos militares. reflexões sobre pesquisas de campo. Rio de Janeiro, RJ: FGV, 2009. p. 107-127.

SILVA, Luiz Maurício de Andrade de. Equipes de alta performance. Air Space Power Journal em Português, Montgomery, v. 19, n. 3, p. 24-31, 3. trim. 2007.

SILVA, Tomaz Tadeu da. A produção social da identidade e da diferença. In: SILVA, Tomaz Tadeu da (org.) Identidade e diferença: a perspectiva dos estudos culturais. Petrópolis, RJ: Vozes, 2000.

SOARES, Samuel Alves. In: CASTRO, Celso; MARQUES, Adriana (org.).

Pesquisando os militares brasileiros. experiências de cientistas sociais. Curitiba, PR: Prismas, 2016. p. 263-303.

TAKAHASHI, Emília. Cadetes pioneiras na AFA: algumas considerações sobre a pesquisa, o campo e a pesquisadora. In: CASTRO, Celso; LEIRNER, Piero (org.). Antropologia dos militares. reflexões sobre pesquisas de campo. Rio de Janeiro, RJ: FGV, 2009. p. 53-74.

WOODWARD, Kathryn. Identidade e diferença: uma introdução teórica e conceitual. In: SILVA, Tomaz Tadeu da (org.). Identidade e diferença: a perspectiva dos estudos culturais. 15. ed. Petrópolis, RJ: Vozes, 2000. p. 7-72. 